\title{
NARRATIVA TRANSMÍDIA UM CONCEITO EM CONSTRUÇÃO
}

\section{NARRATIVE STORYTELLING A CONCEPT UNDER CONSTRUCTION}

\author{
Adriana Landim Quinaud ${ }^{1}$, Esp. \\ Maria José Baldessar², Dra. \\ (1) Universidade Federal de Santa Catarina \\ e-mail:adrilq@gmail.com \\ (2) Universidade Federal de Santa Catarina \\ e-mail:mbaldessar@gmail.com
}

Palavras-chave: jornalismo digital; convergência de mídias; experiência do usuário.

\begin{abstract}
Resumo: O advento das novas mídias alterou a forma de produção e consumo da informação. As notícias que tinham seu formato monomídia, passam a ter seu conteúdo distribuído entre diferentes formatos. Assim, na era da cultura da convergência, surge uma nova forma de comunicar, a narrativa transmídia. Este artigo através do método close reading tem como objetivo analisar seus aspectos utilizados no TAB, projeto editorial interativo do portal UOL. A partir de seus resultados propõe-se que o conceito de narrativa transmídia seja pensado levando em consideração critérios mais flexíveis, reconhecendo que no cenário midiático atual em constante mudança faz do conceito um termo em construção e não algo fechado e em definitivo. O fundamental é focar nos comportamentos e nas práticas que incentiva e possibilita.
\end{abstract}

Key-words: digital journalism; convergence of media; user experience.

Abstract: The advent of new media has changed the way of production and consumption of information. The news had their Monomedia format, now have their content distributed among different formats. Thus, in the convergence culture era, a new way to communicate, transmedia narrative. This article aims to analyze its aspects used in the $T A B$, interactive editorial project of the UOL portal through the close reading method. From the results, it is proposed that the concept of transmedia narrative might be thought considering more flexible criteria, recognizing that in the current media scenario in constant change, makes the concept a term under construction and not something closed and definitive. The key is to focus on the behaviors and practices that the transmedia narrative encourages and enables.

\section{Introdução}

A revolução digital possibilitada pela Internet transformou o comportamento da sociedade como um todo em muitos aspectos, entre eles, na forma de comunicar e interagir consigo, com o outro e com o ambiente. Os meios elétricos proporcionaram o surgimento do que (McLuhan, 1974) chama "aldeia global". O autor explica no seu livro "Os meios como extensões do homem" que o fenômeno da aldeia global faz com que as informações e fatos possam ser narrados em tempo real, dando a sensação de que o território e o espaço são menores. Assim, McLuhan previu a convergência midiática e a globalização com a qual vivenciamos na cibercultura. $O$ ciberespaço torna a comunicação mais prática e rápida; auxilia no compartilhamento e no armazenamento de dados; viabiliza a formação de grupos virtuais; incentiva que leitores procurem e escolham as informações que querem receber, e, principalmente, emitam
Realização:
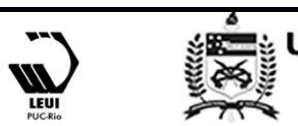


\section{$16^{\circ}$ \\ ERGODESIGN USIHC CINAHPA}

suas opiniões. A cultura participativa (Jenkins, 2008) ganha relevância e os consumidores se tornam ativos e começam a interagir e a produzir conteúdo com/para o produto que consumem, proporcionando um cenário mais democrático. Jenkins aponta para o fato do consumo agora ser um processo coletivo, baseado no conceito de inteligência coletiva de Pierre Lévy. "Nenhum de nós pode saber de tudo; cada um de nós sabe de alguma coisa; e podemos juntar as peças, se associarmos nossos recursos e unirmos nossas habilidades" (2009, p.30).

Nesse contexto, segundo Santos (2016) faz-se necessário repensar a prática jornalística, adaptando-a as possibilidades oferecidas pelas novas mídias e pela reconfiguração dos processos de recepção que se tornaram uma preocupação comum aos meios de comunicação especialmente aqueles inseridos em um mercado movido pela interação com os leitores e produtores de informação da era digital. De acordo com a Pesquisa Brasileira de Mídia 2015, 67\% dos brasileiros utilizam a internet para se informar. As mudanças ocorridas têm apontado para um novo panorama no jornalismo ao indicar o crescimento de novos hábitos de leitura. Ferreiro e Palácio [1987], apontam que o processo de leitura é dotado de uma série de opções. O leitor não responde apenas aos estímulos do meio, e sim desenvolve estratégias para trabalhar com o texto a fim de que seja possível entendê-lo. O que foi possibilitado pela Internet em que imagens, sons, infográficos e inclusive games contribuem dando sentido para as novas práticas informativas. Essa nova capacidade de informar de maneira mais dinâmica unindo diversos suportes para a construção que (Jenkins, 2008) chama de narrativa transmídia (NT), é uma nova estética que surgiu em resposta à convergência das mídias e proposto como formato ideal para a prática da inteligência coletiva. A NT segundo (Jenkins, 2009) é o contar de uma história por meio de diversas mídias, sendo que cada novo texto contribui de maneira distinta e valiosa para o todo. Em sua estrutura ideal, cada mídia deve fazer o que faz de melhor para que seja possível introduzir uma história em diferentes mídias. Essas devem gerar conteúdos que as conectem de alguma forma, mas sem torná-las dependentes. No ponto $16^{\circ}$ Ergodesign - Congresso Internacional de Ergonomia e Usabilidade de Interfaces Humano Tecnológica: Produto, Informações Ambientes Construídos e Transporte

$16^{\circ}$ USIHC - Congresso Internacional de Ergonomia e Usabilidade de Interfaces Humano Computador

CINAHPA | 2017 - Congresso Internacional de Ambientes Hipermídia para Aprendizagem.

de vista do autor, é fundamental que seja possível consumir apenas um meio, e que este viabilize a compreensão da narrativa. Esse ponto merece destaque, pois talvez seja o aspecto que mais gere dúvidas na hora de considerar uma narrativa transmídia ou multimídia.

O interesse principal de Jenkins foi estudar os novos formatos interativos da televisão, que combinam vídeo, envolvimento participativo de fãs através da rede, espaços de afinidade e redes sociais para contar histórias em múltiplas mídias e com vários níveis de interação nos distintos ambientes narrativos. Jenkins defende que a transmídia envolve elementos de uma história disseminada por vários canais de mídia, com uma intertextualidade entre esses elementos; ou seja, a transmídia deve ser distributiva e participatória na sua abordagem narrativa. Isso está relacionado com a ideia de hiperserial de Murray (1997), que a autora reconhece como anterior à argumentação de Jenkins e menos focada na televisão como um texto principal (Murray, 2012). Nesse estudo a NT é utilizada levando em consideração que esse termo sofre o impacto de um cenário midiático em constante transformação (Meyers; Krabbenhoft McKnight, 2013). Murray (2012) problematiza a questão argumentando que já que não entendemos mais os distintos "canais" por "mídia" (isto é, nós vemos "tv" em nossos telefones, tablets e laptops, em qualquer lugar), o termo é tanto datado quanto pouco representativo do nosso pensamento e do nosso comportamento em relação aos sistemas textuais. Nesse sentido, uma visão coerente entre os estudiosos é a de que uma narrativa independente de ser apoiada em produtos licenciados ainda não representa uma verdadeira experiência transmídia. Para (Meyers; Krabbenhoft McKnight, 2013) a análise transmidiática se baseia menos na decisão do que é ou não é transmídia, ou melhor, a partir de critérios rígidos. A análise construtiva da narrativa transmídia exige o reconhecimento do fato de que o cenário midiático em permanente mudança faz do conceito um alvo em movimento. O fundamental é focar nos comportamentos e nas práticas que a narrativa transmídia incentiva e apoia principalmente as práticas literárias relacionadas ao engajamento com a história. Segundo os autores, transmídia não
Realização:

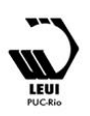




\section{$16^{\circ}$ \\ ERGODESIGN USIHC CINAHPA}

se limita a mídia e a canais de tecnologia, mas na relação com práticas literárias emergentes que estimulam o envolvimento com a narrativa. $\mathrm{O}$ que é a proposta deste estudo, demonstrar como o leitor pode se envolver ao ter acesso a uma reportagem elaborada nesse formato digital inovador.

Reportagem que busca o aprofundamento do conteúdo através do uso de diferentes formatos de mídia, escolhendo sua trajetória de leitura ou experiência de leitura, seu nível de envolvimento, suas necessidades de obter mais informações e de compartilhar suas impressões e opiniões.

\section{Revisão Bibliográfica}

De acordo com (Canavinhas, 2012) a história dos mass media mostra que cada novo meio passa por um período de indefinição até consolidar um conjunto de características próprias. Isto significa que os novos meios começam por misturar os conteúdos dos seus antecessores (remediação) até estabilizarem uma linguagem própria

(convergência). Essa cultura da convergência está presente de diferentes maneiras no nosso dia a dia, como por exemplo, na revista que traz matérias sobre a telenovela, na internet que disponibiliza conteúdos sobre filmes em cartaz no cinema, nos games que geram experiências sobre o seriado televisivo, entre muitos outros. Desse modo, uma das formas de compreender cenário contemporâneo para (Santos, 2016) é observar a relação da sociedade com a mídia que é marcada justamente pela cultura da convergência. De acordo com a autora, Jenkins nomeou algo que já ocorria como sintoma e efeito do aporte digital. Sendo assim, a convergência deve ser pensada como uma mudança cultural, na qual as diferentes mídias coexistem e os produtores e consumidores têm suas relações e papéis alterados. Em outras palavras, é o que (Jenkins, 2009) pontua de constituir pontos de contato com um público mais crítico e participativo, e que se comporta de modo volúvel, indo facilmente buscar informações e entretenimento proporcionados por diferentes plataformas e em variados formatos de conteúdos. O que representa a modificação nas relações entre tecnologias existentes, indústrias, mercados, gêneros e públicos. $16^{\circ}$ Ergodesign - Congresso Internacional de Ergonomia e Usabilidade de Interfaces Humano Tecnológica: Produto, Informações Ambientes Construídos e Transporte

$16^{\circ}$ USIHC - Congresso Internacional de Ergonomia e Usabilidade de Interfaces Humano Computador

CINAHPA | 2017 - Congresso Internacional de Ambientes Hipermídia para Aprendizagem.

Para (Santos, 2016) o emaranhado de informações que caracteriza a NT compõe uma estrutura semelhante à de uma rede, em que os pontos se conectam para compor o todo. A rede digital viabiliza a noção de transmídia ou multimídia em função de sua abrangência e pontos de contato com múltiplos segmentos. Uma vez imerso nessa rede, o consumidor segue os desdobramentos de uma temática por meio de várias mídias. Nesse sentido, a autora argumenta que é inevitável pensar a convergência como integração de múltiplos textos para criação de uma narrativa ampla capaz de se desfragmentar em narrativas menores. Uma NT desenvolve-se como um todo que se estrutura por diversas partes, e cada uma delas interage de modo a produzir um sentido textual e informativo mais amplo. "Os ambientes intertextuais não somente comunicam e informam, mas também, proporcionam ao usuário ações interativas de caráter lúdico". (RENÓ, 2012, p. 46) Segundo Renó, nesses ambientes, o labirinto de informações é decisivo para compor a forma final do conteúdo. Para quem o acessa, prevalece a ideia de liberdade de escolha proporcionada ao leitor - cabe a ele definir por onde começar e terminar a leitura, e os modos particulares de apropriação e acesso a novas camadas informativas, tornando a NT mais atrativa por suas possibilidades.

Por outro lado, (Pernisa Júnior, 2010) considera difícil visualizar a prática do jornalismo transmidiático. $\mathrm{O}$ autor argumenta que o que se vê, na maioria das vezes, são modelos de veículos analógicos sendo transportados para o meio digital. Ele defende o pensamento de Jenkins como base conceitual, porém ressalta a necessidade de não se prender ao conceito, uma vez que toda a sua teoria está baseada no entretenimento e no marketing. $\mathrm{O}$ autor enxerga o jornalismo transmidiático como uma proposta conceitual, que deve ser vista a partir do ponto de vista da experimentação e não de uma realidade consumada. Esse ponto de vista parece ter relação com o aspecto de estar em constante transformação, isto é, em construção. O conceito de NT é aplicável à prática do jornalismo, que, em sua concepção mais básica, refere-se ao ato de contar histórias. E por isso, tem despertado a atenção dos jornalistas principalmente no que se refere a chamar o público à participação, sendo 


\section{$16^{\circ}$ \\ ERGODESIGN USIHC CINAHPA}

através de vídeos, fotos, comentários, entre outros, que complementam o conteúdo a partir de seus celulares ou equipamentos similares. A proliferação dos canais informativos faz com que os jornalistas produzam conteúdos diferenciados e em vários níveis de aprofundamento de modo a contentar públicos distintos. Os agentes da informação procuram encontrar formas para fidelizar seus públicos, preocupação antes reservada aos publicitários e aos criadores da indústria midiática. Assim, vemos surgir o jornalismo de imersão, de associação de games a noticiários, o jornalismo participativo e o jornalismo trasmidiático. No entanto, esse último por ser muito recente e ainda em construção, é muito provável que seu conceito nem sempre seja aplicado da maneira mais próxima à da proposta de Jenkins.

Nesse sentido, a união da informação com o formato multimídia é a forma escolhida pelo $\mathrm{TAB}$, projeto editorial interativo, para apresentar suas reportagens especiais o que permite que o usuário tenha experiências variadas ao acessá-las. Nas palavras do TAB: "Nossa missão é entregar uma experiência única e interativa com conteúdo de alta qualidade, em formatos inovadores e com total independência editorial". O que parece ir ao encontro do que Jenkins argumenta sobre a NT oferecer uma experiência única e interativa, entre outros aspectos. Nessa interatividade muitas vezes os leitores completam os gaps deixados pela narrativa. $\mathrm{O}$ que também pode ser analisado pelo ponto de vista de (Eco, 2003) sobre a obra aberta. Para o autor, qualquer obra apresenta de algum tipo de abertura e é ambígua por natureza, por ser um sistema polissêmico cuja atualização se dá somente quando for fruído. Essa fruição de certo modo respeita as características internas à obra, mas na perspectiva individual do fruidor, a sua situação existencial concreta, um conjunto de fatores que contribuem para determinar a completude e a qualidade da experiência. Um dos aspectos mais interessantes do seu estudo é atentar para o fato que em determinadas poéticas a ambiguidade e a abertura se tornam "uma das finalidades explícitas da obra, um valor a se realizar em preferencia a outros" (ECO, 2003, p.22). $16^{\circ}$ Ergodesign - Congresso Internacional de Ergonomia e Usabilidade de Interfaces Humano Tecnológica: Produto, Informações Ambientes Construídos e Transporte

$16^{\circ}$ USIHC - Congresso Internacional de Ergonomia e Usabilidade de Interfaces Humano Computador

CINAHPA | 2017 - Congresso Internacional de Ambientes Hipermídia para Aprendizagem.

\section{Método}

O método utilizado para analisar a reportagem é o close reading ou leitura profunda, procedimento que envolve um posicionamento crítico, análise e desconstrução da narrativa. Através desse método ao analisar a reportagem Internet das Coisas veiculada no TAB UOL é essencial entender o seu contexto. A fim de chegar a esse entendimento é necessário enquadrar o texto para responder a algumas questões. Como foi recebido o texto? Qual a sua origem? A que responde? Como transforma o texto o significado de outros textos? Quando, onde, quem, para quê e para quem são as questões colocadas para enquadrar o texto no seu contexto. Por outro ponto de vista, o enquadramento/contexto responde a algumas das questões básicas colocadas na prática do jornalismo para a construção da notícia: Quem? O que? Onde? Quando? Como? E por quê?

A leitura close está se tornando uma abordagem comum para a compreensão de "textos" eletrônicos, como videogames e experiências interativas, especialmente entre os pesquisadores da área digital das ciências humanas.

\section{Objeto de Análise}

Fundado em abril de 1996 e pertencente ao Grupo Folha, o portal Universo Online, conhecido como UOL, o pioneiro em conteúdo noticioso online no Brasil. Segundo o seu site ${ }^{1}$, o UOL possui mais de 7,4 bilhões de páginas vistas todos os meses e sua home page recebe mais de 50 milhões de visitantes únicos por mês, contando com mais de 1000 canais de notícias e 7 milhões de páginas. Em outubro de 2014 o UOL lança o $\mathrm{TAB}^{2}$, um novo projeto com proposta de interatividade. Toda segunda-feira (dia da semana campeão em número de acessos) o TAB trás gratuitamente uma nova reportagem com

\footnotetext{
${ }^{1}$ Disponível em: http://sobreuol.noticias.uol.com.br/ Acesso em 10 de novembro de 2016.

2 Disponível em http://noticias.uol.com.br/ultimasnoticias/redacao/2014/10/13/uol-lanca-o-tab-novoprojeto-editorial-interativo.htm. Acesso em $10 \mathrm{de}$ novembro de 2016.
}

Realização:
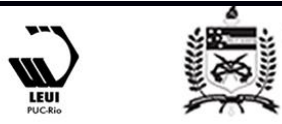


\section{$16^{\circ}$ \\ ERGODESIGN USIHC CINAHPA}

temas provocativos e conteúdo dinâmico caracterizado por pautas diferenciadas, não factuais, exploradas de forma a convergir tecnologia e informação. Uma particularidade da proposta editorial é sua aparente atemporalidade. Segundo o UOL o objetivo do TAB é prender a atenção do leitor, e não apenas gerar cliques escolhido um tema e trabalhado de maneira aprofundada como uma grande reportagem multimídia contendo vários elementos: linguístico, sonoro, icônico ou estilístico (CANAVILHAS, 2007). Diniz (2011, p. 9) diz que "a reportagem, principalmente aquela que é trabalhada como uma série especial, independentemente da mídia principal utilizada, é o gênero que mais facilmente poderia conter partes da narrativa em outras mídias".

Este estudo analisa a edição \#46 (todos os TABs são identificados pela hashtag que indica a semana de sua veiculação desde o número 01 ) com o tema Internet das Coisas. As reportagens do TAB no geral apresentam os seguintes elementos: textos, fotos ou ilustrações (algumas reportagens utilizam ilustrações no lugar das fotografias para melhor ilustrar o texto), vídeos, áudios, infográficos, mapas, comics, testes e/ou games. Aqui cabe ressaltar, que por esses aspectos o $\mathrm{TAB}$ pode ser visto tanto como um formato multimídia apenas ou como uma narrativa transmídia levando em consideração que na proposta deste estudo o conceito de NT é considerado ainda em construção e sem critérios rígidos que o defina.

Abaixo serão mostradas imagens quase em sequência da reportagem que conta a história de uma expedição, conforme é mencionada no texto $100 \%$ online, onde um grupo de exploradores navega pelo delta de Okavango em Angola. Toda a expedição é registrada graças a Internet das Coisas, tudo que é registrado é colocado na nuvem e os smartphones são os dispositivos que tornam essa tecnologia acessível. Shah Selbe, engenheiro da expedição, usa a IOT para falar com a equipe do TAB e essa mesma tecnologia é usada por sensores para monitorar o Okavango. Dessa forma, podemos verificar que a própria forma de a reportagem abordar o tema é diferenciada, pois se trata de uma expedição online o que a princípio a permite ser contada através de uma narrativa $16^{\circ}$ Ergodesign - Congresso Internacional de Ergonomia e Usabilidade de Interfaces Humano Tecnológica: Produto, Informações Ambientes Construídos e Transporte

$16^{\circ}$ USIHC - Congresso Internacional de Ergonomia e Usabilidade de Interfaces Humano Computador

CINAHPA | 2017 - Congresso Internacional de Ambientes Hipermídia para Aprendizagem.

transmídia.

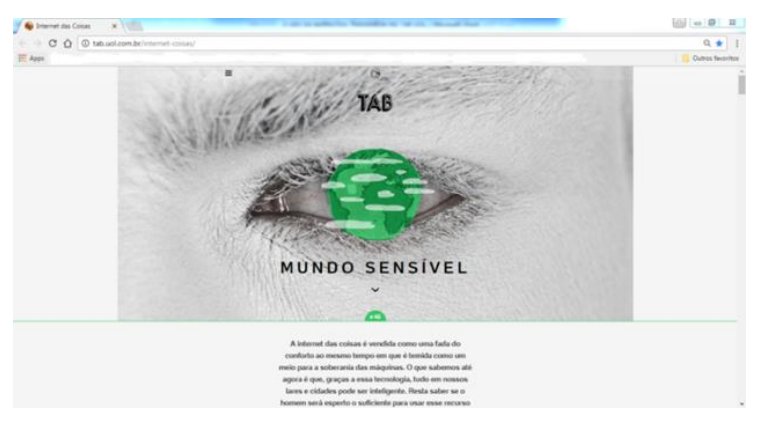

Figura 1 - Imagem animada inicial da edição \#46 Título Mundo sensível (http://tab.uol.com.br/internet-coisas/).

Fonte: Texto: Marco Britto, Design: René Cardillo e Fotografia: Reinaldo Canato. Acesso em: 10 novembro de 2016.

A reportagem analisada inicia como mostra a figura 1 com uma grande imagem que cobre toda a largura da tela, essa imagem contém movimentos (o Planeta Terra girando e as nuvens) com aparência de um GIF animado. Logo abaixo dessa imagem aparece um pequeno texto que apresenta o tema que no seu final questiona se o homem saberá usar essa tecnologia em benefício de sua verdadeira casa, o planeta. Essa abordagem representa bem a proposta do TAB em trabalhar os temas de forma inovadora e provocativa. Para pensar nos aspectos elencados por Jenkins ao definir o conceito de narrativa transmídia constatase que a imagem dinâmica, em oposição ao conteúdo estático tradicional, atrai o leitor por aparentar um aspecto de simulação da rotação do Planeta e uma possível interpretação quanto à analogia entre as nuvens que o circulam e o armazenamento em nuvem que representa uma das características primordiais da internet das coisas. 


\section{$16^{\circ}$ \\ ERGODESIGN USIHC CINAHPA}

$16^{\circ}$ Ergodesign - Congresso Internacional de Ergonomia e Usabilidade de Interfaces Humano Tecnológica: Produto, Informações Ambientes Construídos e Transporte

$16^{\circ}$ USIHC - Congresso Internacional de Ergonomia e Usabilidade de Interfaces Humano Computador

CINAHPA | 2017 - Congresso Internacional de Ambientes Hipermídia para Aprendizagem.

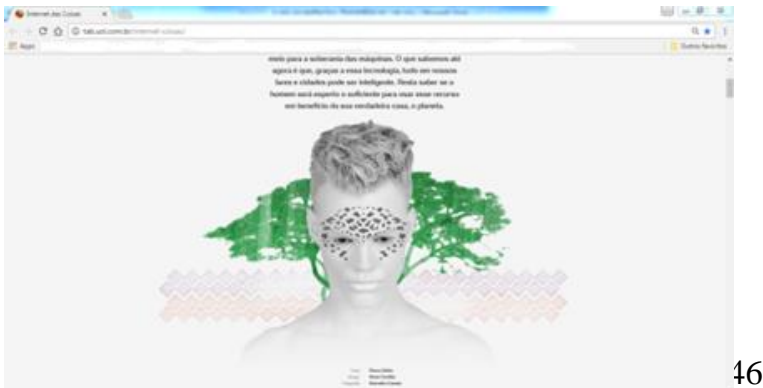

Título Mundo sensível (http://tab.uol.com.br/internet-coisas/).

Fonte: Texto: Marco Britto, Design: René Cardillo e Fotografia: Reinaldo Canato.

Acesso em: 10 novembro de 2016.

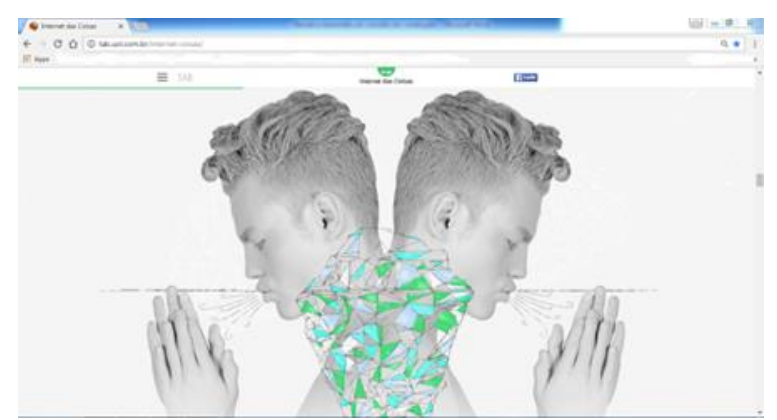

Figura 3 - Terceira imagem animada da edição \#46 Título Mundo sensível (http://tab.uol.com.br/internet-coisas/).

Fonte: Texto: Marco Britto, Design: René Cardillo e Fotografia: Reinaldo Canato.

Acesso em: 10 novembro de 2016.

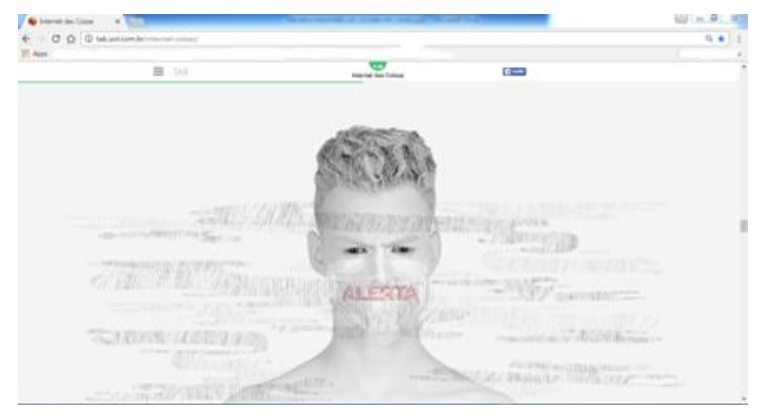

Figura 4 - Quarta imagem animada da edição \#46 Título Mundo sensível (http://tab.uol.com.br/internet-coisas/).

Fonte: Texto: Marco Britto, Design: René Cardillo e Fotografia: Reinaldo Canato.
Acesso em: 10 novembro de 2016.

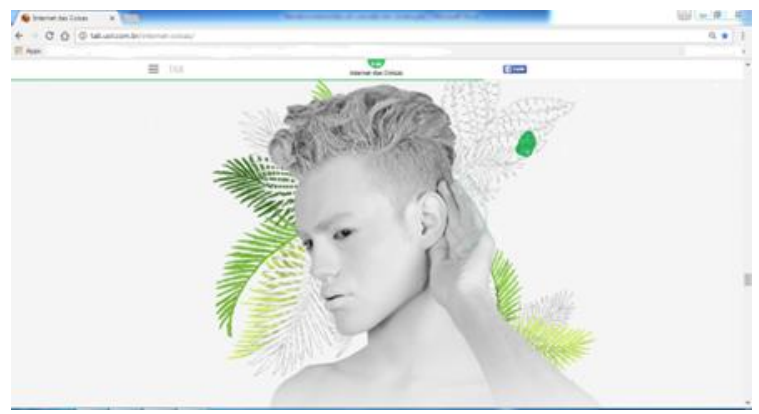

Figura 5 - Quinta imagem animada inicial da edição \#46 Título Mundo sensível

(http://tab.uol.com.br/internet-coisas/).

Fonte: Texto: Marco Britto, Design: René Cardillo e Fotografia: Reinaldo Canato.

Acesso em: 10 novembro de 2016.

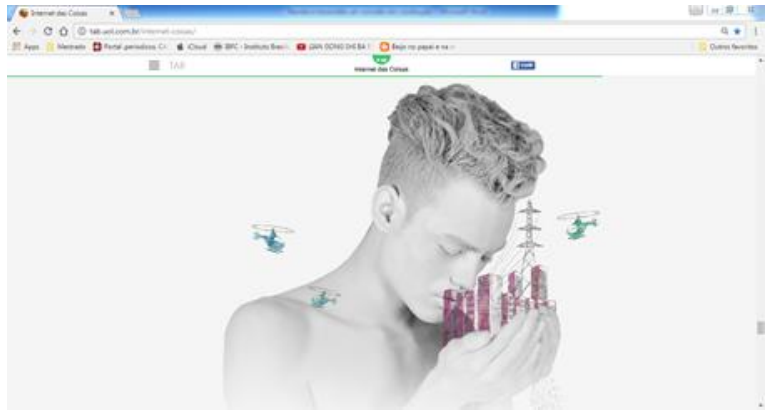

Figura 6 - Imagem animada inicial da edição \#46 Título Mundo sensível

(http://tab.uol.com.br/internet-coisas/).

Fonte: Texto: Marco Britto, Design: René Cardillo e Fotografia: Reinaldo Canato.

Acesso em: 10 novembro de 2016.

As ilustrações animadas são o recurso mais utilizado na reportagem, ao todo foram cinco, em substituição as fotografias para representar de forma artística algum aspecto relacionado à parte do texto com as quais estão associadas. Na imagem da primeira ilustração animada, a árvore e o "homem-animal" faz alusão ao ambiente onde ocorre a expedição e mencionada no texto, o Pantanal africano. A animação é feita através do animal (tigre) que é inserido no rosto da personagem. A imagem da segunda ilustração animada mostra o movimento do iceberg e o sopro do ar polar que ilustram a parte da reportagem que relata sobre o monitoramento da qualidade de água
Realização:

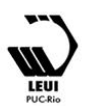




\section{$16^{\circ}$ \\ ERGODESIGN USIHC CINAHPA}

no oceano Antártico. Na imagem da terceira ilustração animada, a palavra alerta pica piscando em vermelho em cima da máscara de proteção respiratória representando o perigo da poluição do ar mencionada nessa parte da reportagem. A imagem da quarta ilustração animada mostra a movimentação das plantas e da verberação do som no ouvido do personagem que pode ser interpretado de diferentes maneiras. Essa parte do texto fala sobre o mapeamento da floresta sulamericana, feito pelo dispositivo Mãe d'Água, que mede a qualidade da água mostrando na hora se há contaminação. Os moradores da região podem receber a informação em seus telefones celulares, portando a ilustração do som reverberando pode representar o som dessas ligações ou pode representar de um modo geral a importância de se atentar para os dados que o aparelho indica. E por último, a quinta ilustração animada com o personagem tendo nas mãos com a cidade com destaque para o poste de energia e os helicópteros que se movimentam como se estivessem sobrevoando a cidade. A animação ilustra a parte da reportagem que relata como as grandes empresas veem a distribuição de energia como a primeira fronteira urbana a ser revolucionada pela internet das coisas.

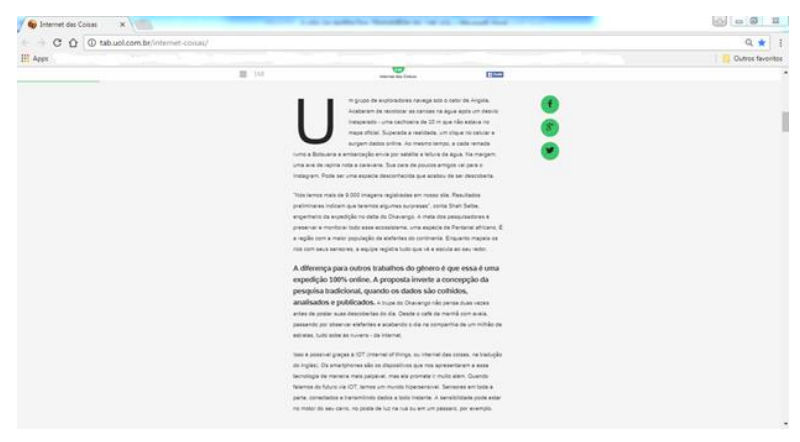

Figura 7 - Texto inicial acompanhado com links para compartilhamento -

Facebook, Google+e Twitter.

Acesso em: 10 novembro de 2016.

Depois da apresentação do tema e a ilustração animada, começa a reportagem com possibilidade de compartilhamento pelas mídias sociais $16^{\circ}$ Ergodesign - Congresso Internacional de Ergonomia e Usabilidade de Interfaces Humano Tecnológica: Produto, Informações Ambientes Construídos e Transporte

$16^{\circ}$ USIHC - Congresso Internacional de Ergonomia e Usabilidade de Interfaces Humano Computador

CINAHPA | 2017 - Congresso Internacional de Ambientes Hipermídia para Aprendizagem.

Facebook, Google + e Twitter. Esse aspecto é o que Jenkins pontua como participação ativa do leitor. A cultura da participação são os seus valores, interesses e propósitos que definem o que tem valor ao ponto de merecer ser propagado. É importante enfatizar a importância do público neste processo, pois todo material propagado é refeito. Seja de modo figurado, quando o conteúdo é inserido em conversas por meio de diversas plataformas; ou de modo literal, quando o conteúdo é sampleado ou remixado. Logo, o público é um propagador e um gerador de conteúdo. É peça essencial em um mundo onde o que não se propaga, morre (Jenkins; Green; Ford, 2014, p. 234). Para que uma mídia, ou um conteúdo, torne-se propagável, é imprescindível que recursos técnicos sejam disponibilizados. $\mathrm{O}$ objetivo da mentalidade propagável é criar conteúdos que "vários públicos possam espalhar por diferentes motivos, convidando as pessoas a moldar o contexto do material conforme o compartilham no âmbito de suas redes sociais" (Jenkins; Green; Ford, 2014, p. 29).

Através do Facebook além de adicionar seu comentário/opinião é possível escolher a forma de compartilhar a publicação seja na linha do tempo, em um grupo ou como mensagem privada. Há também a possibilidade de marcar pessoas, fazer check-in e adicionar o que está fazendo ou sentido. No Google + o compartilhamento segue a mesma lógica possibilitando o comentário, a definição do público e adicionar pessoas. O Twitter cria automaticamente um tweet: "O dia em que rios e focas mandam e-mails chegou. Graças à internet das coisas verdes http://tab.uol.com.br/internetcoisas/ \#uoltab \#uol \#internet-coisas" e insere o link da URL para o compartilhamento da reportagem. Assim, a propagabilidade se dá de forma orgânica e é o público que toma a decisão.

Realização:




\section{$16^{\circ}$ \\ ERGODESIGN USIHC CINAHPA}

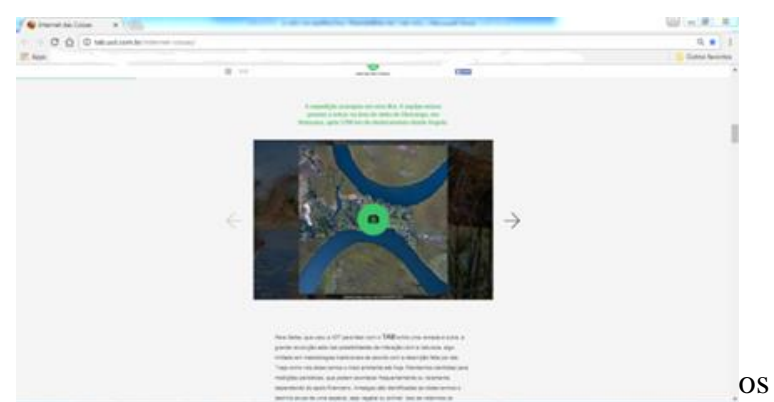

Fonte: James Kydd/Into The Okavango 2015 Acesso em: 10 novembro de 2016.

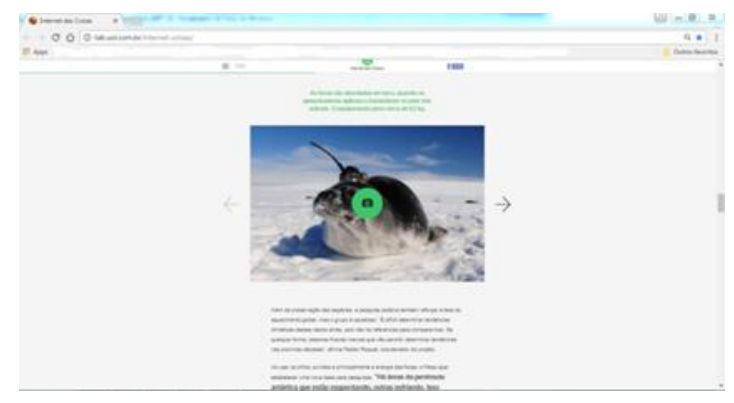

Figura 9-Slideshow 2 com sequência de cinco fotos Fonte: Fonte: Dan Costa/Meop Acesso em: 10 novembro de 2016.

As fotografias seguidas do texto escrito são um dos principais elementos utilizados no projeto TAB. De acordo com Ferreira (2003, p. 4) "a imagem fotográfica na web, assim como no impresso, em certas ocasiões assume o papel de texto autônomo". No jornalismo a fotografia há muito tem seu espaço conquistado e bem explorado pelo fotojornalismo, por tanto não representa novidade. O que pode ser destacado a respeito do que é mostrado na figura 4 como um aspecto transmídia seja a forma como os dois slideshows foram feitos reunindo sequências de fotos acompanhadas de legendas que ilustram o texto expondo diferentes fases da expedição como se fosse um making of, recurso bastante utilizado atualmente que mostra o que acontece nos bastidores da produção de um conteúdo audiovisual. $16^{\circ}$ Ergodesign - Congresso Internacional de Ergonomia e Usabilidade de Interfaces Humano Tecnológica: Produto, Informações Ambientes Construídos e Transporte

$16^{\circ}$ USIHC - Congresso Internacional de Ergonomia e Usabilidade de Interfaces Humano Computador

CINAHPA | 2017 - Congresso Internacional de Ambientes Hipermídia para Aprendizagem.

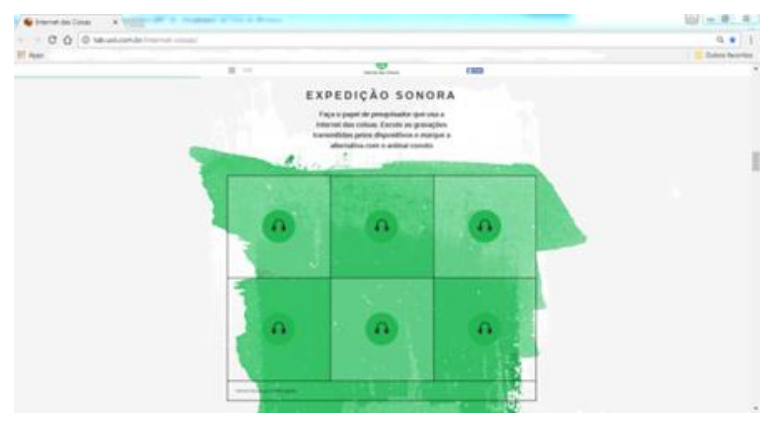

Figura 10 - Expedição Sonora experiência auditiva (antes da interação)

Acesso em: 10 novembro de 2016.

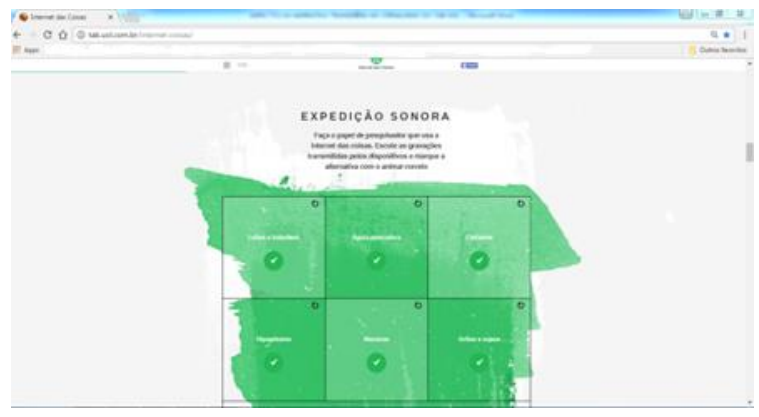

Figura 11 - Expedição Sonora experiência auditiva (depois da interação)

Acesso em: 10 novembro de 2016.

O recurso do áudio costuma ser utilizado com depoimentos, com sons que ilustram ou ambientalizam a reportagem ou agregam música e informações como uma grande reportagem radiofônica. Neste caso, é o ponto máximo da reportagem \#46 quando ao aspecto da narrativa transmídia, pois além de utilizar o áudio para completar todos os outros recursos que já vem sendo explorados pela reportagem convida o usuário à interatividade. A reportagem disponibiliza seis áudios com sons característicos de diferentes animais que faz com que o leitor tenha uma experiência como pesquisador. Através da narrativa e da internet das coisas o leitor/pesquisador escuta as gravações com os sons de animais locais transmitidas pelos dispositivos e marca entre três alternativas a que corresponda ao animal que produz aquele som podendo verificar a resposta correta. Por exemplo, no primeiro áudio com duração de 18 segundos, mostrados pelo cronômetro, aparecem as seguintes alternativas: a) tigres e hienas, b) guepardos e zebra e c) leões e 


\section{$16^{\circ}$ \\ ERGODESIGN USIHC CINAHPA}

$16^{\circ}$ Ergodesign - Congresso Internacional de Ergonomia e Usabilidade de Interfaces Humano Tecnológica: Produto, Informações Ambientes Construídos e Transporte

$16^{\circ}$ USIHC - Congresso Internacional de Ergonomia e Usabilidade de Interfaces Humano Computador

CINAHPA | 2017 - Congresso Internacional de Ambientes Hipermídia para Aprendizagem. babuínos. Como se pode verificar, sons nada comuns de serem identificados o que acaba sendo uma experiência única e enriquecedora no sentido de descobrir qual o som corresponde a qual animal e se revelar um aspecto da narrativa transmídia.

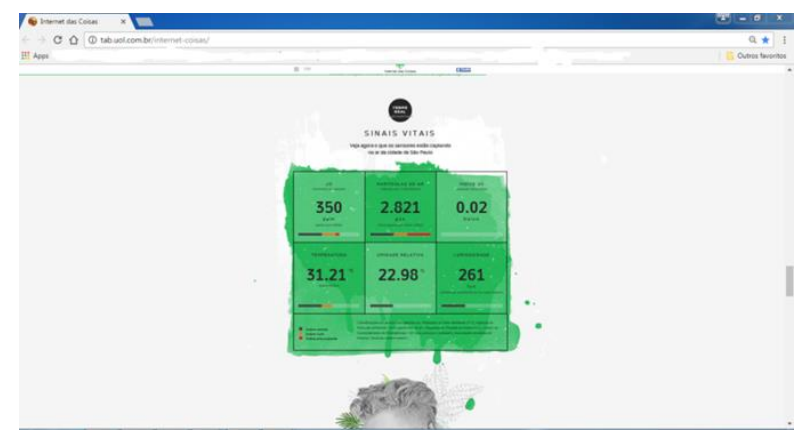

Figura 12 - No tempo real - Sinais vitais Acesso em: 10 novembro de 2016.

Nessa parte da reportagem é explorado outro aspecto interessante da narrativa com o uso do recurso em tempo real (em constante atualização) que vem sendo muito utilizado no webjornalismo e que bem caracteriza a cultura da convergência. $\mathrm{Na}$ reportagem é demonstrado o que os sensores estão captando no ar da cidade de São Paulo e uma legenda indica se o status é normal, ruim ou preocupante. Os sensores indicam o número de monóxido de carbono presente no ar, número de partículas no ar, radiação ultravioleta, temperatura, umidade relativa e luminosidade. $\mathrm{O}$ que ilustra a parte da reportagem que relata sobre a metade da população do planeta viver em áreas urbanas, onde o ar e a água são os recursos mais ameaçados. A proposta desse formato seria bem interessante se a atualização permanecesse ativa mesmo depois de sua disponibilização já que uma das características do conteúdo digital é sua perenidade. Mas ao ser analisada em novembro, mesmo ano de sua produção, os dados já se mostram estáticos.

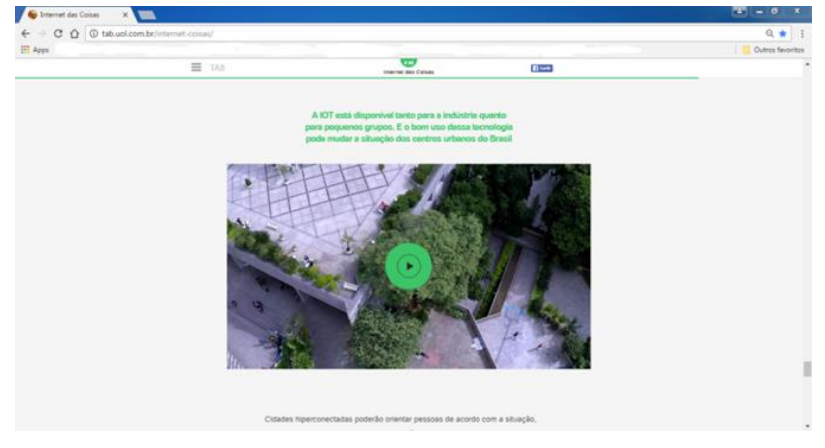

Figura 13 - Imagem do vídeo disponibilizado Acesso em: 10 novembro de 2016.

A reportagem conta com um vídeo de 4 minutos e 56 segundos com depoimentos de dois profissionais de empresas diferentes ilustrando o tema. O formato do vídeo é diferente de uma reportagem convencional veiculada na televisão, pois não apresenta repórter, passagem e off. Tem maior semelhança com documentários, em que as personagens narram sua história em primeira pessoa intercalando com adição de imagens onde o que está sendo dito ganha destaque. No aspecto narrativo, a reportagem \#46 como foi demonstrada até agora, já explorou o formato texto escrito, as imagens animadas, os slideshow de fotos, os áudios e fecha com o vídeo que é a personificação do conteúdo através dos depoimentos que geram a identificação dos leitores, pois exemplificam de fato no dia a dia das pessoas devido à relação de proximidade. $\mathrm{O}$ fato do formato do vídeo ser diferenciado em que o depoimento dos personagens parece ser de forma espontânea representando a realidade que vivem, ao contrário de um vídeo de uma reportagem tradicional na qual a presença do repórter já parece querer induzir o rumo da entrevista e do depoimento. 


\section{$16^{\circ}$ \\ ERGODESIGN USIHC CINAHPA}

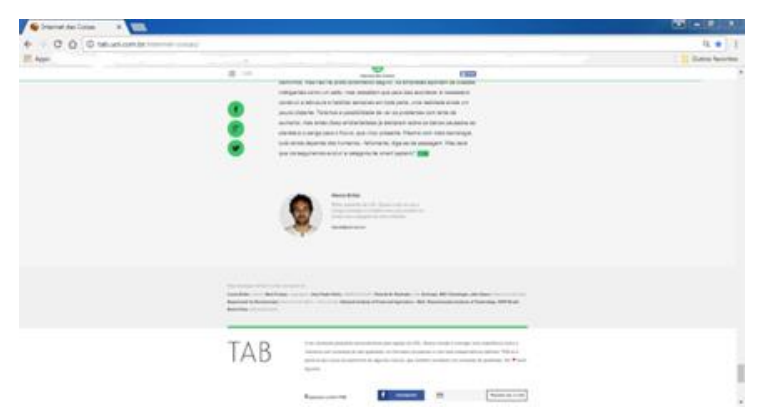

Figura 14 - Encerramento da reportagem Acesso em: 10 novembro de 2016.

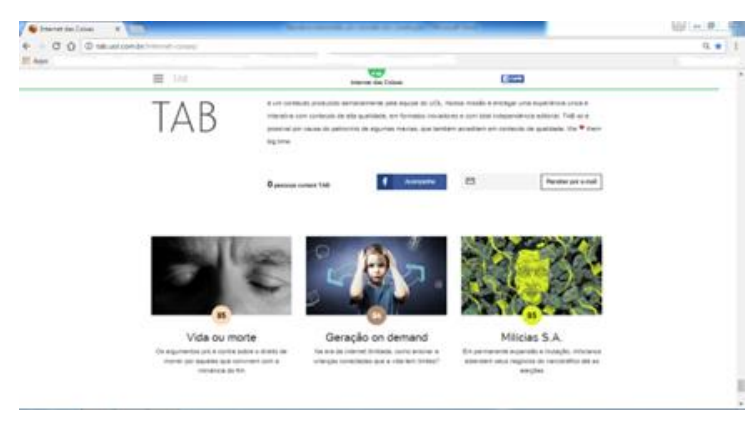

Figura 15 - Encerramento da reportagem Acesso em: 10 novembro de 2016.

Por fim, a reportagem chega ao fim com a identificação do editor-assistente (além de no rodapé identificar também toda a equipe de apoio) o e-mail de contato da redação do TAB o que representa um canal de feedback oferecido ao leitor e o link de acesso para acompanhar o Facebook do TAB. Novamente é disponibilizado os três canais de redes sociais (Facebook, Google+ e Twitter) para compartilhamento do conteúdo o que parece indicar a importância que esse representa para o projeto TAB. E por último são disponibilizados as imagens de três reportagens com seus números de identificação, título, breve resumo, link de acesso ao conteúdo e um box com a possibilidade de acessar todas as demais, Ver todos.

\section{Resultados e Considerações finais}

O interesse desse estudo é analisar se a reportagem \#46, produzida pelo TAB pode ser considerada ou não uma narrativa transmídia. A partir da $16^{\circ}$ Ergodesign - Congresso Internacional de Ergonomia e Usabilidade de Interfaces Humano Tecnológica: Produto, Informações Ambientes Construídos e Transporte

$16^{\circ}$ USIHC - Congresso Internacional de Ergonomia e Usabilidade de Interfaces Humano Computador

CINAHPA | 2017 - Congresso Internacional de Ambientes Hipermídia para Aprendizagem.

concordância de que uma narrativa pode ser desenvolvia em diferentes plataformas, o conceito de transmidiação, uma prática que também deriva da participação do público, necessita ser abordado a partir de suas possibilidades de utilização nessa atividade específica da comunicação, o jornalismo digital. A NT aqui considerada como um termo em construção, não apresenta critérios rígidos que a defina. Portanto, a \#46 se revela uma narrativa transmídia "incompleta" em sua essência. Ou seja, apresenta aspectos transmídia como os componentes estáticos e dinâmicos, a contribuição única de cada meio, a experiência única e coordenada, diferentes pontos de entrada e a participação e interatividade do público. Portanto, não se trata de uma narrativa multimídia que segue uma sequencia de leitura linear, enquanto a narrativa transmídia é aleatória. $\mathrm{O}$ projeto $\mathrm{TAB}$ possibilita a participação do usuário não somente na navegação pelos conteúdos, como também a partir da distribuição desses conteúdos pelas redes sociais. A interatividade acontece através da experiência, nesse caso, como pesquisador na identificação dos sons dos animais. Vale destacar que o TAB poderia incluir espaços na própria reportagem para comentários, sugestões e críticas, algo como um fórum ao fim da matéria que permitisse os leitores discutir sobre o tema da semana. Mas por outro lado, a reportagem \#46 apresenta um ponto crítico que no que se refere à dependência de um meio a outro para completar sua compreensão. O que contraria a proposta de Jenkins que aponta a independência de cada meio seja fundamental para a sua compreensão. Esse fato por si só, nessa proposta, não invalida seus outros aspectos, assim como dito anteriormente sobre seu conceito está em movimento no sentido de caminhar para sua completude, de estar em construção.

\section{Conclusão}

A revolução digital acarretou uma transformação cultural na mente e no comportamento da sociedade. A horizontalidade nas relações entre emissor e receptor se torna cada vez mais necessária. É a cultura da participação que ganha cada vez mais espaço. A convergência é um processo em andamento e a narrativa
Realização:
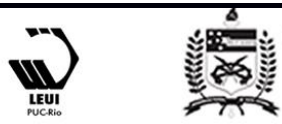


\section{$16^{\circ}$ \\ ERGODESIGN USIHC CINAHPA}

$16^{\circ}$ Ergodesign - Congresso Internacional de Ergonomia e Usabilidade de Interfaces Humano Tecnológica: Produto, Informações Ambientes Construídos e Transporte

$16^{\circ}$ USIHC - Congresso Internacional de Ergonomia e Usabilidade de Interfaces Humano Computador

CINAHPA | 2017 - Congresso Internacional de Ambientes Hipermídia para Aprendizagem. transmidiática é uma das formas como a convergência vem ocorrendo, portanto pode ser pensada como um termo em construção. $\mathrm{O}$ exemplo do TAB mostra que na reportagem \#46 alguns elementos da narrativa transmidiática já foram incorporados ao processo de convergência de conteúdo. Isso se verificou pelo uso de uma narrativa transmídia ainda que de forma "incompleta" na busca de superar limitações de tempo (programa de TV), espaço (revista impressa) e periodicidade. Pode-se inferir que a narrativa transmídia no que se refere ao jornalismo digital demonstra caminhar no sentido de produções que visem objetivos de aprofundamento das temáticas e dos pontos de vistas explorados. No caso do TAB, na reportagem \#46 esse aprofundamento do ser verificado quando a redação acompanha uma expedição que acontece e simultaneamente é registrada. Além da compreensão obtida por meio de diferentes mídias, o que gera uma profundidade de experiência e oportunidades de compartilhamento. Consequentemente, é o caminho para as grandes reportagens, pois o leitor está cada vez mais engajado e interessado em interagir com o conteúdo e com seus elementos escolhendo seu próprio roteiro de leitura. Desse modo, a narrativa transmídia analisada de forma mais flexível, pode reconhecer que nas mudanças do cenário midiático atual seu conceito revela-se um termo em construção, não podendo ser definido de forma fechada, concreta. O fundamental da experiência transmídia é focar nos comportamentos e nas práticas que ela incentiva e possibilita, ou seja, na relação com práticas literárias emergentes que estimulam o envolvimento e a participação com a narrativa. $\mathrm{O}$ leitor deixa de ser mero espectador para fazer parte do cenário narrado. Portanto, é necessária a produção de reportagens transmídia com usabilidade e que levem em conta a experiência do usuário em outras plataformas. O que significa que mesmo sendo um formato inovador, faz parte da história de experiência do usuário e não uma forma de inventar formas de sinalizar o escape, a saída de um link, o acesso a imagens, textos e outros recursos.

Por fim, ressaltamos que as mídias digitais ainda não foram completamente entendidas quanto ao seu potencial e portanto sofrem questionamentos. $\mathrm{O}$ conceito de narrativa transmidiática aparece como uma estratégia que se adequa ao momento de revolução cultural proporcionado pelas mídias digitais. Há ainda muita desconfiança a respeito do conceito em si, sendo que pesquisas futuras podem colaborar na construção de uma definição que se encaixe melhor ao um contexto em constante transição.

\section{Bibliografia}

BRASIL. Presidência da República. Secretaria de Comunicação Social. Pesquisa brasileira de mídia 2015: hábitos de consumo de mídia pela população brasileira. - Brasília: Secom, 2014.

CANAVILHAS, João. Webnoticia: propuesta de modelo periodístico para la WWW. Cavilhã: Labcom, 2007.

CANAVILHAS, João. A remediação à convergência: um olhar sob os media português, Brazilian Journalism Research, 8(1), 15.

DINIZ, Talita Rampazzo. (In) conclusões sobre a narrativa transmídia no jornalismo: sobre o que pode ser e o que se deseja. Trabalho apresentado ao DT 1 Jornalismo do Congresso de Ciências da Comunicação na Região Nordeste realizado de 15 a 17 de junho de 2011. Disponível em: <http://intercom.org.br/papers/regionais/nordeste2 011/resumos/R28-0833-1.pdf>. Aceso em: 10 jul. 2015.

ECO, Umberto. Obra aberta: Forma e indeterminação nas poéticas contemporâneas. $9^{\mathrm{a}}$ ed. São Paulo: Perspectiva, 2003.

FERREIRO, E. PALÁCIO, M. G. Os Processos de Leitura e Escrita: novas perspectivas. Porto Alegre: Artes Médicas, 1987.

JENKINS, Henry. Game design as narrative architecture. 2007. Disponível em: <http://web.mit.edu/21fms/People/henry3/games\& narrative.html> Acesso 09 jul 2015. 


\section{$16^{\circ}$ \\ ERGODESIGN USIHC CINAHPA}

JENKINS, Henry. Cultura da convergência: a colisão entre os velhos e novos meios de comunicação. Trad. Susana Alexandria. São Paulo: Aleph. 2008.

JENKINS, Henry; GREEN, Joshua; FORD, Sam. Cultura da conexão: criando valor e significado por meio da mídia propagável. São Paulo: Aleph, 2014.

LÉVY, Pierre. Cibercultura. (Trad. Carlos Irineu da Costa). São Paulo: Editora 34, 2009.

MEYERS, Eric M.; KRABBENHOFT, Lindsey; MCKNIGHT, Julia. A Remidiação de Sininho: explorando os fundamentos da transmídia em um sistema narrativo secular. Leitura: Teoria \&

Prática, Campinas, v.31, n.61, p.13-41, nov. 2013.

MCLUHAN, Marshall. Os Meios Como

Extensões do Homem. São Paulo: Cultrix, 1974. MURRAY, J. H. Hamlet in The Holodeck: The future of narrative in cyberspace. New York: Free Press, 1997.

\section{MURRAY, J. H Transcending transmedia:}

Emerging story telling structures for the emerging convergence platforms. In: Proceedings of the 10th European Conference on Interactive TV and Video(Euroitv'12), p.1-6, ACM, New York, NY/USA, 2012.

\section{PERNISA JÚNIOR, Carlos. Jornalismo}

Transmidiático ou Multimídia? Trabalho apresentado no Congresso Brasileiro de Ciências da Comunicação - Intercom, Caxias do Sul, RS, 2010. Revista Interin. v. 10, n. 2, 2010. Disponível em:<http://interin.utp.br/index.php/vol10/article/vi ew/18> Acesso em: 10 de nov. 2016.

RENÓ, D.; FLORES, J. Periodismo transmedia. Madrid: Fragua, 2012.

SANTOS, Maria Stella G. O uso da narrativa transmídia para revigoração do gênero reportagem. Revista Latino-americana de Jornalismo, João Pessoa/PB, Ano 3 vol.3, n.p. 66 a 80 , jan/jun.2016. $16^{\circ}$ Ergodesign - Congresso Internacional de Ergonomia e Usabilidade de Interfaces Humano Tecnológica: Produto, Informações Ambientes Construídos e Transporte

$16^{\circ}$ USIHC - Congresso Internacional de Ergonomia e Usabilidade de Interfaces Humano Computador

CINAHPA | 2017 - Congresso Internacional de Ambientes Hipermídia para Aprendizagem.

UOL, TAB. Site Oficial. Disponível em:

< http://tab.uol.com.br/>. Acesso 10 nov. de 2016 